\title{
Technology, Proximity, and Measures of Kin Support
}

\author{
EUGENE LITWAK \\ Columbia University \\ STEPHEN KULIS* \\ Arizona State University
}

\begin{abstract}
The proposition is advanced that many current measures of kinship strength may paradoxically indicate inadequate or weakened kinship structures. That is so because they rely on measures that emphasize continuous proximity. This curious paradox is a consequence of inattention to the relationship between technology, services, and proximity. This article presents nonproximity indicators of kinship contact and service delivery that can measure strength of kinship bonds, and states the principles for assessing at what distances kin can deliver which services.
\end{abstract}

The concept of the modified extended family structure, introduced in 1960 , was based on three considerations: $(a)$ that kin structures are a necessity in a modern industrial society; $(b)$ that in order for it to live alongside the powerful formal organizational structures, the kin structure had to alter its form to permit differential mobility of kin members; and $(c)$ that it was possible to do this because modern technology permitted the transmission of many crucial services over geographic and social distance (Litwak, 1960). This model of kin structure was contrasted with the traditional one, which stressed the need for kinship proximity or common households, the communality of occupations, and the rejection of nonkin members, such as staff of formal organizations. These two models of kinship were, in turn, opposed by a series of writers who saw either the isolated marital unit as the optimal family unit (Burgess,

Data for this study were gathered under grants from the National Institute of Aging, Grant No. R01 AG04577, and the National Institute of Mental Health, Grant No. R01 MH 30726. However, they cannot be held responsible for the conclusions reached in this article.

School of Public Health, Columbia University, $600 \mathrm{~W}$. 168th Street, New York, NY 10032.

* Department of Sociology, Arizona State University, Tempe, AZ 85281 .
Wallin, and Schultz, 1953; Parsons, 1944) or the individual (Polsky and Duberman, 1979).

In many fields of sociological endeavor, such as gerontology and health, the precise strength of kinship ties has become an important issue. Thus writers have pointed out that social support groups such as kin reduce mortality and morbidity (Berkman, 1985) and provide most of the help that chronically ill older people receive (Kendig, 1983; Shanas, 1979). Yet when it comes to measuring the strength of such ties, there is considerable confusion as to which items should be used and the extent to which they are interchangeable. Should researchers use contact measures that emphasize face-to-face visits or telephone calls? Which of the variety of services are the best indicators that kin are providing exchange, such as food and emotional support? Is the number of kin who live in the same house or the same city the best measure of strength?

In the present study we argue that the items that best measure kin strength cannot be identified until one of the above two models of kinship structure is selected. In fact, from the point of view of the modified-extended-family model, items on proximity typically used by researchers to measure kin strength actually measure kin weakness because they stress a kin structure that is least suited to a modern society, or one that is in a state of crisis. In order to make this point clear, we also 
address the relationship between technology, proximity, and the delivery of kin services.

\section{THE RELATIONSHIP BETWEEN TECHNOLOGY, SERVICES, AND PROXIMITY}

The first step is to understand that services, like groups, vary enormously in their dependence on geographic proximity. There are at least two underlying dimensions that relate services to the need for proximity (Litwak, 1985). These are (a) the extent to which services require face-toface contact, and $(b)$ the frequency with which the service must be delivered to be viable. For example, services that require daily or hourly face-toface contact, such as personal grooming and providing food for chronically ill persons, demand continuous close proximity. In contrast, some services do not require face-to-face contact because they can be managed over the phone. Furthermore, these services may be less frequent. Providing emotional support to a long-term widow by weekly phone calls is an example.

There are, of course, mixed cases, where the two dimensions go in different directions. For instance, providing household help for someone who is bedridden for two or three weeks requires daily face-to-face contact, but it is an infrequent event. It is possible for a helper to fly in from far away, deliver the services, and fly back home. Some services are frequent but do not require face-to-face contact. For example, it is sometimes necessary to telephone frail older people every day to make sure they are all right. Such calls can be made at some distance before they become too costly.

The question arises, how does technology intervene in this process? To understand its role, a small mental experiment is illuminating. Consider an earlier time when the major forms of transportation were walking or using a horse-drawn vehicle. In that context, further contemplate three services: $(a)$ providing emotional support to a recent widow by talking to her two or three times a week, $(b)$ providing household help to a husband and children while the wife has been put in the hospital for two weeks, and (c) providing daily food to a person who is chronically ill and can no longer manage ordinary household tasks. In this earlier time all three services required close continuous proximity if one family member were to help out another. The development of the telephone liberated the first service from the demands of immediate proximity. People could provide very frequent emotional support to a recent widow and still live a considerable distance away. It took the development of the automobile and the airplane to liberate temporary household help from the demands of continuous proximity. However, there is no current technology that has liberated the provision of daily household services by a kin member from the demands of geographic proximity.

We argue that geographic proximity is not a simple dichotomy. Some activities can be provided by those who live within a 10 -block radius but not farther, some can be provided by those who live within a 5 -mile radius but not farther, and so on. Given the complexity of the issue it is hard to state a priori how far away an individual can be and still deliver services. Yet the concept of the modified extended family requires such knowledge, as does the simple empirical observation that kin are the major source of help for older people (Kendig, 1983; Shanas, 1979).

\section{Services and Proximity}

To make clear the advantages of an explicit analysis of proximity and type of service, we examine nine services delivered by the chief helper of older people. These data come from a 1978 stratified random area sample survey of 1,346 people, 65 or older, half living in the New York City metropolitan area and half living in the Fort Lauderdale-Miami area of Florida (Litwak, 1985). Elderly respondents were asked if their chief helper had provided these services within the last six months. The helper was, by definition, a son or daughter, if the older person had one, and if not, a primary group member other than a spouse. $^{2}$ Respondents were asked about four "house services" ordinarily provided by spouses, namely, light housekeeping (such as making beds), laundry or storing things, helping with money matters (such as keeping track of bills), and helping to fix small things around the house.

In addition, respondents were asked about a series of services that could be managed by the larger kin unit because they were either infrequent or could be handled over the phone. These are referred to as "normal kin services" and include checking daily to see if the older people are all right, taking them out for dinner or having them over, giving them small household gifts (such as bedspreads, plants, or TV sets), helping them keep in touch with other family members, and talking to them when they are feeling upset to make them feel better.

In order to measure the effects of distance, all helpers were classified in terms of how far they lived from the respondent, either physically or temporally. ${ }^{3}$ The percentage of respondents receiving services at each distance is presented in Table 1. These percentages are used as the best 
Table 1. Percentages of Older Persons Receiving Services from Helper, by Distance from Helper and TYPE OF SERVICES

\begin{tabular}{|c|c|c|c|c|c|}
\hline \multirow[b]{2}{*}{ Type of Services } & \multicolumn{4}{|c|}{ Distance Older Person Lives from Helper } & \multirow[b]{2}{*}{$\begin{array}{l}\text { Rate } \\
\text { of } \\
\text { Decline }\end{array}$} \\
\hline & $\begin{array}{c}\text { Same } \\
\text { House } \\
(n=179)\end{array}$ & $\begin{array}{c}\text { One to Five } \\
\text { Blocks } \\
(n=202)\end{array}$ & $\begin{array}{l}\text { Six Blocks to } \\
30 \text { Minutes } \\
(n=335)\end{array}$ & $\begin{array}{c}\text { Over } \\
30 \text { Minutes } \\
(n=598)\end{array}$ & \\
\hline & \multicolumn{4}{|c|}{ Marital Household Services } & \\
\hline Doing light housekeeping & $82(77)$ & $26(26)$ & $12(10)$ & $06(08)$ & $57(49)$ \\
\hline Doing laundry, storage, cleaning & $74(75)$ & $23(28)$ & $14(16)$ & $09(15)$ & $48(37)$ \\
\hline $\begin{array}{l}\text { Managing money, household bills, } \\
\text { social security }\end{array}$ & $58(49)$ & $25(25)$ & $20(20)$ & $12(16)$ & $40(30)$ \\
\hline Doing small household repairs & $81(85)$ & $39(48)$ & $30(35)$ & $14(21)$ & $43(37)$ \\
\hline \multirow[t]{2}{*}{ Average for all marital household services } & $74(72)$ & $28(32)$ & $19(20)$ & $10(15)$ & \multirow[t]{2}{*}{$47(39$} \\
\hline & \multicolumn{4}{|c|}{ "Normal" Kin Services } & \\
\hline Checking on respondents daily & $99(95)$ & $85(86)$ & $64(61)$ & $20(23)$ & $36(34)$ \\
\hline Providing dinner for respondents & $82(78)$ & $67(68)$ & $59(57)$ & $36(40)$ & $23(20)$ \\
\hline Providing small household gifts & $79(72)$ & $49(48)$ & $47(44)$ & $35(38)$ & $22(18)$ \\
\hline \multirow{2}{*}{\multicolumn{5}{|c|}{$\begin{array}{l}\text { Helping respondents keep in touch } \\
\text { with relatives }\end{array}$}} & \\
\hline & $75(69)$ & $44(45)$ & $42(40)$ & $42(45)$ & $15(11)$ \\
\hline Cheering respondents when low & $92(87)$ & $83(83)$ & $79(78)$ & $70(73)$ & $09(07)$ \\
\hline Average for all "normal" kin services & $85(80)$ & $66(66)$ & $58(56)$ & $41(44)$ & $21(18)$ \\
\hline
\end{tabular}

Note: The figures in parentheses are the percentages computed with the following elements controlled: the respondent's health, marital status, kin norms, ethnicity, number of children, affection for the helper, age, and education. In addition, the gender and marital status of the helper was controlled. The standardized percentages were derived from the regression equations in Table 2.

estimates of the probability of the services being delivered at each distance. Since there are other factors that can affect services (other than technology), such as the needs and resources of the individual, we also estimated the effects of proximity while controlling for the more obvious needs and resources, such as state of health, marital status, age, gender, educational level, ethnic status, notions of filial responsibility for older parents, affection for the helper, the number of children of the respondent, and the gender and the marital status of the helper. The standardized percentages of persons receiving each service at each distance were derived from the regression coefficients in Table 2 and are located in parentheses next to the unstandardized figures in Table 1. The differences between the standardized and unstandardized figures are small, on average only $2.7 \%$. This is consistent with a view that the need for household help (e.g., because of illness or poverty) can best be satisfied by the helper and the older person moving closer together. ${ }^{4}$

With this point in mind, it is readily apparent from Table 1 that services vary radically in the extent to which they are affected by distance. Using the standardized percentages, one can see that when the older person and the helper live in the same household, $77 \%$ of the older people receive light housekeeping help. However, if the older person lives only a small distance away, from one to five blocks, there is a major drop of $51 \%$, with only $26 \%$ receiving this service. For the respondents who live the farthest away from their helper, over 30 minutes, only $8 \%$ receive light housekeeping services. The pattern for other services, such as being cheered up when feeling low, is very different. Those living in the same household as their helper are quite likely to receive this service $(87 \%)$, much like housekeeping $(77 \%)$. However, in sharp contrast to the delivery of light housekeeping services, those who provide emotional support are much less affected by incremental changes in distance. Thus, $83 \%$ of the people who live from one to five blocks away from their helpers receive emotional support, a drop of only $4 \%$ from those who live in the same household. If one examines older people who live the farthest away, over 30 minutes, $73 \%$ still receive emotional support when they are feeling low, but only $8 \%$ receive light housekeeping services.

To give a rough idea of the relationship of each service to geographic distance, we have computed geographic decline rates. ${ }^{5}$ Light housekeeping has an average decline rate of .49 , while cheering people up when feeling low has a decline rate of .07 . The former is far more severely affected by geographic distance than the latter. Between these two extreme items, as Table 1 indicates, there is a continuum of effects, with the marital household services having geographic decline rates that range 


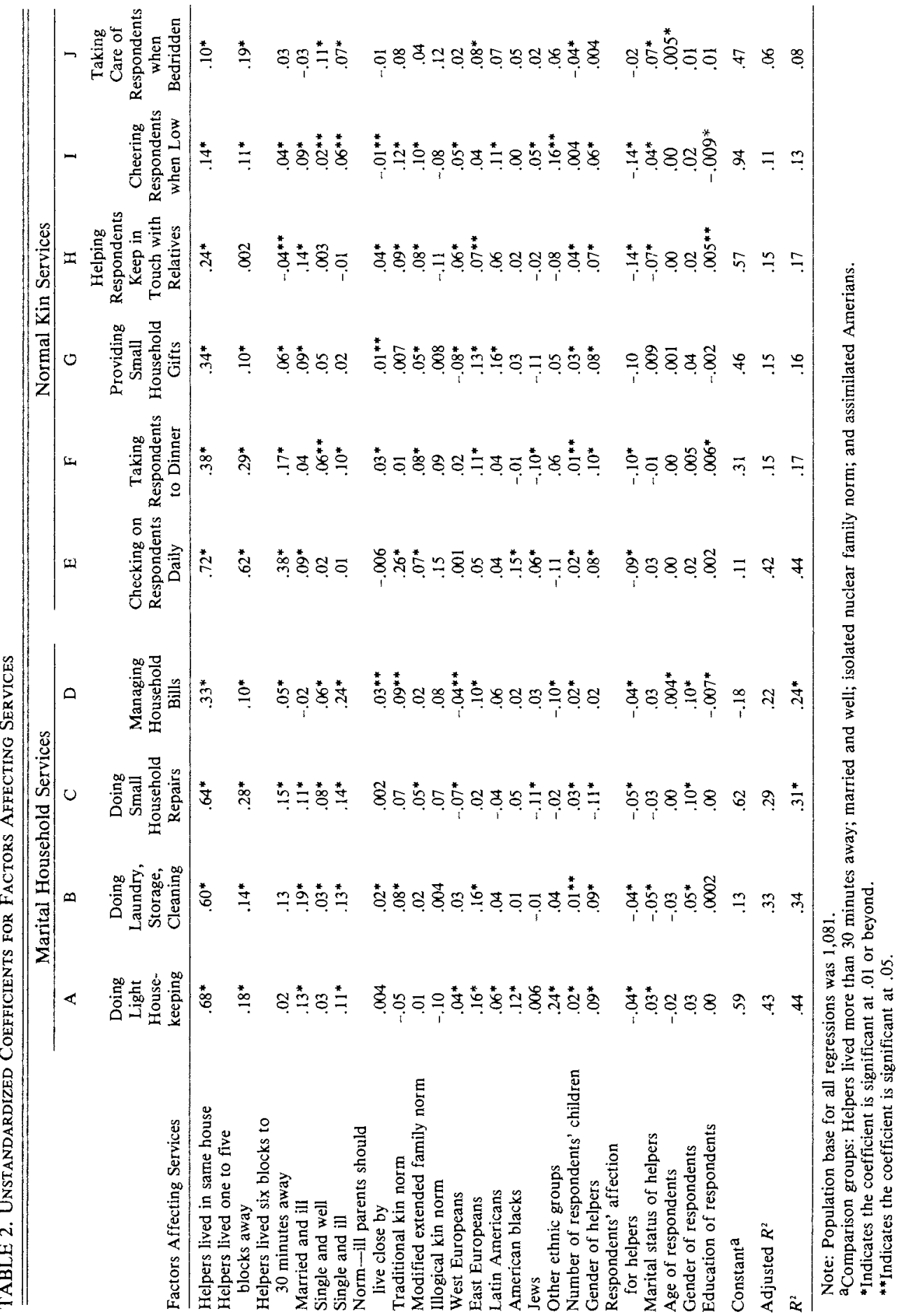


from .49 to .30 and the normal kin services having rates that range from .34 to .07 .

While common sense suggests that providing household services requires closer proximity than providing emotional support, it is surprising that living only one to five blocks away drastically lowers the probability of getting household help to $26 \%$. The precise patterns that relate each task to proximity permit a more accurate prediction of which services kin members can provide under varying social contingencies such as states of health. This point can be made more clearly if the number of household services is related to proximity. If a respondent is relatively healthy and therefore needs help from kin on only one household service, then, as Table 3 indicates, there is a $94 \%$ chance of getting it if the helper lives in the same household. Those living as far as 30 minutes away still have a $43 \%$ chance of getting the service. However, if the respondent is more disabled and needs help on at least two such services, the helper must live within five blocks for the respondent to have at least a $31 \%$ chance of receiving the help. Those even more disabled and in need of three services would have to live in the same household with the helper if they want more than a $19 \%$ chance of getting help. This analysis permits much more accurate estimates of how far away kin can live at each stage of physical frailty and still deliver the required service.

\section{A General Solution for \\ Classifying Tasks by Proximity}

This increase in precision, however, also introduces a seemingly unmanageable complexity due to the infinite number of distance points and the endless number of tasks. This complexity can be reduced if it is understood that the services depend upon a very small number of technologies (phone, airplane, car, and mail), which involve only a few basic dimensions (the frequency of delivery and the necessity of face-to-face contact). This limited number of technologies and basic dimensions can be related to proximity. Once this relationship is established, the relationship of any given task, present or future, to proximity can be estimated. All that must be done is to specify which technology a given task must use and the frequency with which it must be delivered.

The key to conceptual simplification is to attempt a direct measure of the two underlying properties of technology that affect services, that is, face-to-face delivery and frequency. They are estimated from the following two questions: "How often will you talk with (your helper) on the phone?" "How often will you see (your helper), either at your home, or their home or some other place?" The answers were classified as daily or more frequently, from weekly to daily (but not including daily), from monthly to weekly (but not including weekly), from yearly to monthly (but not including monthly), less frequently, and never. The proportion of people in contact with helpers at each distance is given in Figures 1 and 2.

Since we are arguing that services and technologies have their own requirements for geographic proximity, independent of the need or resources of those helped, the respondents' answers have again been standardized for illness, marital status, education, age, kin norms, ethnicity, number of children, gender, affection for the helper, and the helpers' gender and marital status. This standaradization is derived from the regression coefficients in Table 4.

To illustrate the advantages of using the telephone for technologies requiring face-to-face contact, we shall initially assume that we are dealing with services that can be managed by either technology. For instance, a wife whose husband is seriously ill in the hospital might be emotionally supported by daily conversations either face-toface or by telephone. If people have a choice of

TABle 3. Percentages of Older Persons Receiving Household Services from Helper, by Number of Tasks and Distance from Helper

\begin{tabular}{|c|c|c|c|c|c|}
\hline \multirow[b]{2}{*}{ Number of Tasks } & \multicolumn{4}{|c|}{ Distance from Helpera } & \multirow[b]{2}{*}{$\begin{array}{l}\text { Average } \\
\text { Rate of } \\
\text { Decline }\end{array}$} \\
\hline & $\begin{array}{c}\text { Same } \\
\text { House } \\
(n=179)\end{array}$ & $\begin{array}{l}\text { One to } \\
\text { Five } \\
\text { Blocks } \\
(n=202)\end{array}$ & $\begin{array}{l}\text { Six Blocks } \\
\text { to } \\
30 \text { Minutes } \\
(n=335)\end{array}$ & $\begin{array}{l}\text { Over } \\
30 \text { Minutes } \\
(n=598)\end{array}$ & \\
\hline $\begin{array}{l}\text { One or more household tasks } \\
\text { Two or more household tasks } \\
\text { Three or more household tasks } \\
\text { Four household tasks }\end{array}$ & $\begin{array}{l}94 \\
86 \\
70 \\
45\end{array}$ & $\begin{array}{l}49 \\
31 \\
19 \\
15\end{array}$ & $\begin{array}{l}43 \\
19 \\
09 \\
05\end{array}$ & $\begin{array}{l}27 \\
10 \\
04 \\
01\end{array}$ & $\begin{array}{l}32 \\
50 \\
60 \\
71\end{array}$ \\
\hline
\end{tabular}

In $90 \%$ of the cases the helpers were children or other relatives.

bThe rate of decline is the difference between two adjacent points on the distance scale divided by the closest point. When averaged this gives the "average rate of decline." 
FIG. 1. Standardized Percentages of Respondents in Face-to-Face Contact with Helper, by Distance FROM HELPER

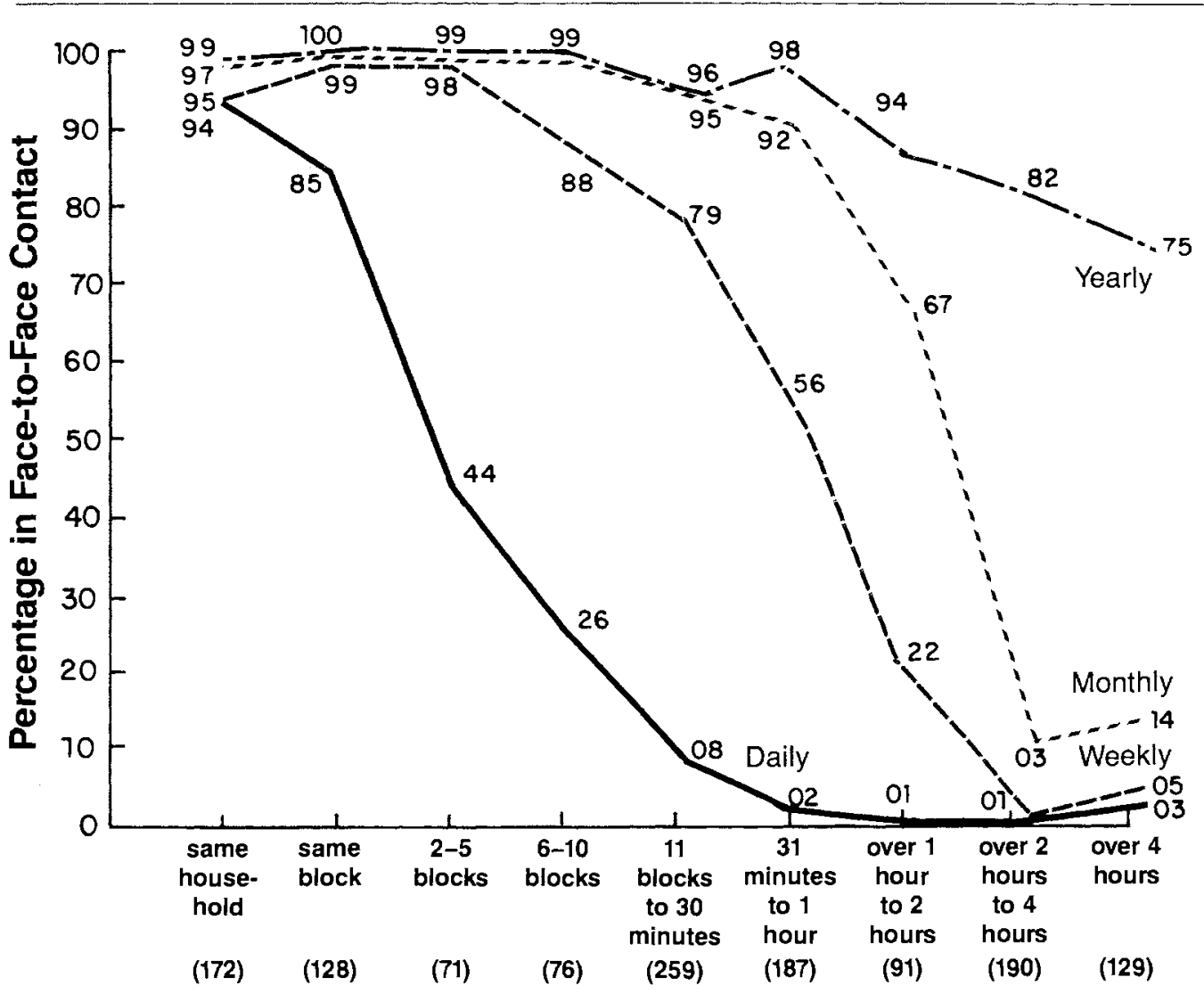

\section{Distance between Helper and Older Person}

Note: Percentages are standardized on illness, marital status, education, age, kin norms, ethnicity, number of children, gender and affection of the respondent, and marital status and gender of helper. Numbers in parentheses are the population base for percentages.

technologies, at what geographic distance does daily telephoning provide a higher probability of delivering services than daily face-to-face contacts?

A comparison of Figures 1 and 2 suggests that for our respondents the advantage of using telephones daily occurs only when people live two blocks away but not more than two hours away. After that point the telephone provides no advantage. Thus, when the distance is between two and five blocks, $82 \%$ of the people in our sample have daily telephone contact with their helper, while this is true of only $44 \%$ of our respondents who have daily face-to-face contacts. However, if a respondent lives more than two hours away, the percentages making daily telephone and face-to- face contact are basically the same, close to zero. For respondents living no more than one block away the two technologies also lead to similar percentages receiving services, but in this case they are high percentages, $85 \%$ and $76 \%$.

Yet another question can now be addressed: How does variation in frequency of the same technology affect the geographic distance at which services can be delivered? For instance, one can have few clothes and do laundry every day or have many clothes and do laundry weekly. When kin must provide laundry services, at what points will lessening the frequency of services permit them to live at a greater geographic distance? Figure 1 suggests that the geographic advantages (which accrue from lowering the frequency of 
Fig. 2. Standardized Percentages of Respondents in Telephone Contact with Helper, by Distance from HeLPER

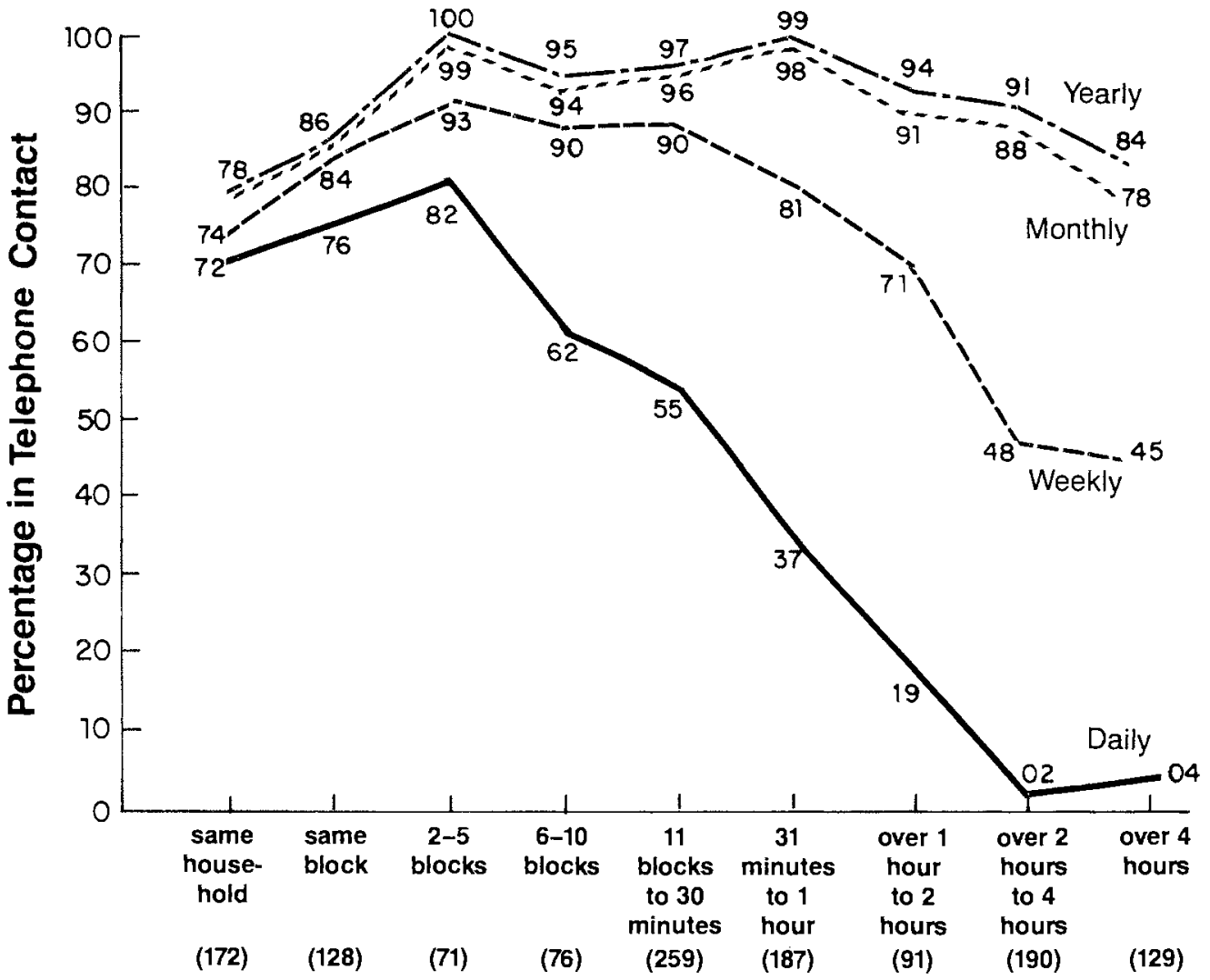

\section{Distance between Helper and Older Person}

Note: Percentages are standardized on illness, marital status, education, age, kin norms, ethnicity, number of children, gender and affection of the respondent, and marital status and gender of helper. Numbers in parentheses are the population base for percentages.

face-to-face contact from daily to weekly) extend from those living on the same block to those living two hours away.

More generally, Figure 1 suggests that if persons in marital household units are intact and healthy and need services requiring face-to-face contact only on a yearly basis, they can live at great distances of more than four hours away and still have a high probability, $75 \%$, of receiving such services. However, if such persons are slightly disabled and require at least monthly face-toface contact, they must live no more than two hours away if they want at least a $67 \%$ chance of receiving the service, and within an hour away if they want a $92 \%$ chance of receiving the service. If the married couple are so disabled that weekly face-to-face contact is needed, they must live within one hour away to have a $56 \%$ chance of getting the service and within 30 minutes away if they want an $88 \%$ chance of getting the service. If they are so disabled or ill that they need daily contact, then they must live within five blocks to have a $44 \%$ chance of getting the service and must live on the same block to have an $85 \%$ chance of getting the service. If they need services that require more than daily contact, they must live in the same household.

This formulation provides a more general theoretical solution to the problem of classifying "infinite" distance points and endless tasks into a manageable number of patterns. Services must be mapped into two underlying dimensions: the degree to which they require face-to-face contact and the frequency of such contact. Figures 1 and 2 


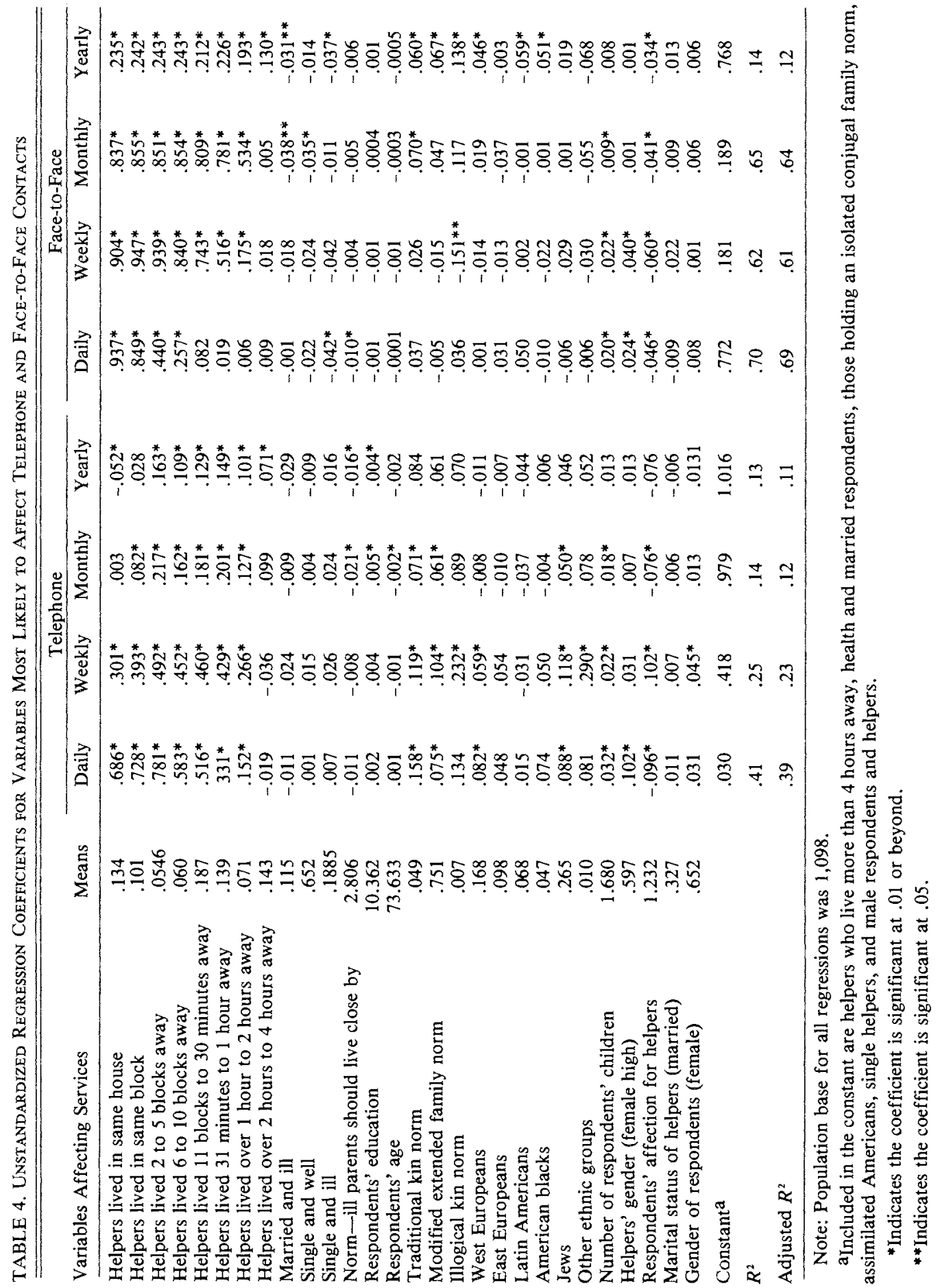


provide the prototype for these two basic patterns. The relationship of all services to proximity can be estimated from the eight curves in these figures, or some combination, once their frequency of contact and degree of "face-to-faceness" is established. However, until there is a representative population sample and most technologies are accounted for, these figures must be considered only prototypical estimates. They enable investigators to study the possible relationship between kinship structure, all tasks, and proximity before the massive empirical job of mapping tasks to proximity has been done.

\section{KINSHIP THEORY AND THE MEASUREMENT OF KINSHIP STRENGTH: A CHOICE OF MODELS}

How does the above discussion bear on the measurement of kinship strength? It is obvious that those who use the delivery of family services as a measure of kinship strength will come to very different conclusions, depending on whether they select services liberated by technology from geographic demands of those not so liberated. For example, Rix and Romashko (1980) argued that the kinship system of older people was not crucial because most services were managed by the individual or his or her spouse. However, the services they used to measure the strength of kin ties were those not liberated by technology, such as daily shopping, cooking, and daily household cleaning. Litwak (1960) argued that groups such as kin were crucial, because his measure of kin strength was emotional succor or identity as expressed in services that could be managed via the telephone and ad hoc visits. To avoid this kind of confusion, it is necessary to have clearly in mind that services vary in the extent to which they require continuous proximity.

In addition, it is necessary to have in mind which theoretical concept of kinship is to be used as a measuring rod. As mentioned above, researchers who measure kinship strength use three kinship models, implicitly or explicitly. In the traditional kinship model, continuous proximity is considered vital to the definition of kin strength. In the second, the modified-extendedfamily model, proximity is seen as a measure of kin weakness and nonproximity services as a measure of strength. With the third model, the isolated marital unit, all kinship ties are viewed as indicators of weakness.

To be more specific, several measures typically used by researchers are very consistent with the traditional kin model, as follows: (a) the number of adult kin who live in the same household or nearby, $(b)$ the number of visits (i.e., face-to-face contacts between kin), and (c) the number of household activities (which technologically require proximity) such as cooking, shopping, laundry, and personal grooming that are provided by kin.

The modified-extended-family model suggests that kinship systems in a modern industrial society are ideally made up of semiautonomous household units (Litwak, 1960; Sussman, 1977). Indicators of kinship strength that measure such a model assume the absence of the above proximity measures and the presence of $(a)$ telephone contacts rather than face-to-face visits; $(b)$ the use of services that are liberated from proximity by technology, that is, services that can be supplied by the telephone, such as emotional succor, monetary help, and advice; and (c) the use of services delivered around major life events, such as death, acute illness, marriage, and birth, because they are infrequent and people can quickly come great distances and return home because of modern technology. As opposed to these two models, the "isolated marital unit or individual" model treats all kinship ties as inconsistent with the needs of a modern industrial society. Thus the ideal kin tie is a minimal one-that is, neither continuous proximity nor services provided occasionally or at a distance are considered measures of strength.

In the past, researchers had very little to go on when selecting items to measure kin strength. They did not know which services to use or if they should use visits, telephone conversations, or some combination. If one keeps in mind the above models of kinship structure, such ambiguity can be reduced.

The choice of a model is, in turn, partly a value decision and partly an empirical one. If one makes the value choice that a democratic industrial society is a desired state, the empirical and theoretical evidence suggests that the modified extended family structure is the ideal kinship structure (Litwak, 1965, 1985; Sussman, 1977). It is argued that the traditional kinship systems' demand that kin live close by and share the same occupation leads to a closed class system in which the poor are kept permanently impoverished. Thus, Anderson (1977) pointed out that until the late 1800s English laws on filial responsibility led to the impoverishment of the children, or to parents and adult children fleeing from each other to avoid this consequence. Young and Willmott (1957) and Gans (1962) pointed out that in more contemporary times, working-class English groups and ItalianAmericans who had a traditional kin concept discouraged their children from educational and occupational mobility. Litwak (1985), using the same data set as presented here, provided 
evidence that those individuals with a traditional family orientation had lower occupational status than those with a modified extended family structure, and furthermore, their children had lower educational achievement.

However, those who recommend a traditional kinship model seldom concern themselves with such issues. They focus on the fact that kin are most likely to provide the critical "household" services to older people who are chronically ill, but they tend to ignore the costs of kinship help. The literature indicates (Horowitz, 1985) that services delivered to older people who have great need can constitute an intolerable social and financial strain on the helpers and their families. What is beneficial for one part of the kin system (e.g., older chronically ill persons) can be disruptive to another part (e.g., the helpers). This suggests a curvilinear relationship between help and kin strength-too little help and too much help can lead to the collapse of the kin system.

In addition, the traditional kinship system is less likely to use formal agencies because of the norms against nonkin members. Horwitz (1977) argues that groups with strong ties (e.g., persons in traditional kin structures) bring their members to doctors at a very late stage in their illness because of their reluctance to deal with outsiders. Gans (1962) points out that Italian families with a strong traditional norm were unable to fight off urban renewal programs that were destroying their community, in part because of their unwillingness to trust "strangers" (i.e., lawyers, social workers, and politicians who were not kin) who offered legal and political power. Litwak and Falbe (1983) found that nursing home residents with a traditional kin orientation had much more difficulty working with nursing home staff than those with a modified extended family orientation.

In addition, Litwak (1985) argues, the modified extended family is less pressured for differential mobility when a member is out of the labor force because of chronic illness. It will not be as close as the typical extended family, but it can supply considerable household support.

Thus, if one considers the isolated marital dyad as a kinship model where aid is minimal, the average percentage of modified extended families receiving household services is midway between the traditional kinship group and the isolated marital dyad. ${ }^{6}$ On the average, $31 \%$ of those with traditional kin norms received one or more household services, as did $25 \%$ of those with modified extended kin norms. This contrasts with $17 \%$ of those who had an isolated marital unit norm.'

In summary, evidence that the traditional kin system provides more household services is not as persuasive if the kind of help offered disrupts other parts of the kin system, prevents older people from getting help in other crucial areas of life, such as medical care, and can lead to a classcrystallized society. By contrast, the modified extended family structure can provide considerable household help without similar negative consequences. This is the grounds for arguing that the modified extended family structure is more consistent with modern industrial society than the traditional kin structure.

The question still remains, in what way is this new kinship structure more desirable than the isolated marital unit (Parsons, 1944) or the individual (Polsky and Duberman, 1972)? The assumption of these latter models that formal organizations can take over most of the services provided by the kin and marital units is theoretically and empirically weak (Litwak and Figueria, 1968). It has been shown that performance of formal organizations can be materially increased when supplemented by primary groups such as kin, in fields such as mass media communication (Katz and Lazarsfeld, 1955), education (Blau, 1981), nursing care (Litwak and Falbe, 1983), health (Berkman, 1985), help during unemployment (Hanlon, 1982), and providing services to older people (Kendig, 1983). If the individual or isolated marital unit provides short-term individual autonomy but leads to significant losses of most other social goals, then this model is not likely to be accepted by most people.

\section{The Modified Kin Model in Crises}

The modified extended kin structure would emphasize continuous proximity where pressure for differential mobility is reduced, and it is weakened by $(a)$ chronic illness, $(b)$ marital disruption, and $(c)$ poverty. The rationale has already been discussed for those who are chronically ill and retired (i.e., out of the labor force). If the standardized coefficients are calculated from Table 2, and a magnitude of at least .10 is used together with a .01 level of significance, then those who are sick (especially sick and single) are likely to receive household services from a helper regardless of kin type or other socioeconomic variables (Litwak, 1985). Therefore, those who use household services as a measure of kin bonds are likely to include kin whose members are sick and single. The same point would be true where the helper in the labor force is single and the kin are retired. The need for coalescence derives from the ineffectiveness of a one-person household for managing household tasks, and the fact of retirement means there is far 
less pressure for differential mobility between parent and adult child. If the older person and his or her child are both single, they are much more likely to live together (29\% of the time) than if they were both married $(4 \%)$. The same is almost as true when the child is single and the older person is married (14\% vs. $4 \%$ ). It is less often the case where the helper is married and the older person is single $(10 \%)$. As already shown, when people live together they are far more likely to get household services. On the average, $76 \%$ of those older people living with their helper received a household service as compared with $16 \%$ of those who did not live with their helper. The evidence suggests a causal chain: the single helper and older person move in together and thereby are better able to deliver household services. ${ }^{8}$ Therefore, people who use household services or proximity as measures of family strength are likely to incorporate a significant number of incomplete marital households.

Still a third circumstance under which the modified extended family may coalesce is when its members are very poor. In such instances they may have no jobs or unskilled ones, which means there will be minimal pressure for differential mobility. If one finds an unskilled job in a new place and there are other job openings, then other kin are technically able to fill the job as well.

In addition, poor people have much greater need of kin services because they cannot afford to use formal organizations. For instance, a poor person who wants to attend a school meeting but needs a baby sitter cannot hire one but must depend on kin or friends to help out. The data show that $25 \%$ of the helpers in the lowest income quartile live in the same household as the older person, and this percentage decreases to $20 \%$ then to $12 \%$ and finally to $5 \%$ as the quartile increases. As Table 2 shows, those who live closer get more household services. ${ }^{9}$ As a result, those who use proximity or household services as measures of family strength will incorporate a significant group of poor families.

In short, measures of kinship aid based on proximity are very likely to measure either inadequate traditional kinship structures or the modified extended one when it is at its weakest state, that is, when members are chronically ill, have broken households, and/or are very poor. For many researchers the objection to such proximity measures will not seem vital, since they see kin structures as inconsistent with modern society. To show that extended kin structures lead to lower goal achievement in an industrial society only verifies this theory. What they overlook is the powerful aid that the modified extended fami- ly members provide which significantly affects the life chances of "well-off" individuals; such aid helps to account for greater life span as well as occupational and educational achievement (Berkman, 1985; Blau, 1981; Litwak, 1985).

\section{Measures of Kin Strength}

With these thoughts in mind, it is now clear why from the perspective of the modified extended family the following types of measures used to indicate kin strength may be measures of kin weakness: $(a)$ frequency of face-to-face contact, $(b)$ number of close relatives who live in the same household or nearby, and $(c)$ the number of household activities (i.e., tasks not as yet liberated by technology) delivered by kin. By contrast, the following "normal kin" services and contacts are indicators of kin strength when the above are not present: (a) frequency of telephone contacts, (b) frequency of services that do not require faceto-face contact (e.g., advice and emotional succor), and $(c)$ frequency of services that require only limited face-to-face contact (e.g., help during acute illness, death of spouse, birth, and marriage). Since these "normal" kin services are also carried out by traditional families, they are measures of the strength of the modified extended family only when they occur independently of household services. To make this point clear, we classified all respondents into four groups-those who received both household services and normal kin services, those who received only normal kin services, those who received only household services, and those who received neither. If a weakened modified kin structure (as indexed by having an older person who is chronically ill and single) is contrasted with a healthy kinship system (as indexed by those who are married and healthy), it can be seen that they differ markedly in terms of their having received one or more household services. Of those sick and single (248), 64\% received one or more household services; of those sick and married or single and healthy (657), $44 \%$ received household services; while of those who were healthy and married (439), 30\% received household services. Thus, the sick and single were almost twice as likely to receive household services that require continuous proximity. If one looks at the normal kin services, there is virtually no difference: $91 \%$ of the sick and single, $89 \%$ of the married and sick or sick and single, and $85 \%$ of the married and healthy received such services. However, if one examined only those cases where the kin exchanged normal kin services but not household services, there are substantial differences: $27 \%$ of the sick and single, $45 \%$ of the married and sick or healthy and single, and $55 \%$ 
of the healthy and married received such services. In short, normal kin services and household services are arranged on a Guttman-type scale, with all families receiving normal kin services but only the traditional and weakened modern types receiving household services. Since there is a third kin type, those who have no kinship ties at all, it is necessary to measure simultaneously both normal kin and household services in order to differentiate the modern kin system from the traditional and from those who are not kin-oriented. Of course, another alternative is to try to measure kin norms directly and not rely on services or generalized contact measures. This becomes a necessity for those wanting to differentiate between the weakened modified kin structure and the traditional one. ${ }^{10}$

\section{SUMMARY AND CONCLUSION}

Modern technology has made possible a very different kinship structure. Insofar as investigators have used measures of continuous proximity as the indicator of kin strength, they have inadvertently proposed a kinship structure that is least consistent with a modern industrial society or one that is weakened by clyronic illness, a broken marital unit, or poverty. This study shows the types of items that can be used to measure kinship strength. In addition, the newer model of kinship structure, the modified extended family, requires a study of the relationship between technology, services, and proximity, a relationship that has been virtually ignored. Given that proximity is often not an ideal state for kin in a modern industrial society, it becomes very important to know how close people must live to kin in order to deliver required services. We have stated the principles for making such an assessment without having to map out empirically the relation between all services and proximity. For those interested in the role of social supports, the issues are not simply which theoretical model and which measure is best, but there is very obvious "practical" importance in establishing at what distances any given form of help can be transmitted. In this instance the pragmatic issues will optimally be solved in conjunction with theory.

\section{FOOTNOTES}

1. Technology may increase or decrease the influences of proximity (Litwak and Figueira, 1968).
2. In $75 \%$ of the cases the helper was a child, in another $15 \%$, a relative other than a child, and in $10 \%$, a friend (Litwak, 1985). Because of space constraints we do not examine the specific effects of helpers' age, gender, type of relation (e.g., child, sibling, friend), or ethnicity. Rather, these and other factors are held constant, as indicated in Table 2.

3. The respondents were asked whether the helper lived in the same household, on the same block, or in the same apartment building, within five blocks, within ten blocks, or farther than ten blocks. If farther than ten blocks, they were asked, "About how long does it take the helper to come to your place?"

4. If the limits of modern technology require household services to be delivered through face-toface contact, the older person's needs and resources will show up as having indirect effects in a causal model, that is, the needs should relate to proximity, which in turn should relate to household services. Litwak (1985: 135-139) provides a path model for this causal sequence.

5. The decline rate consists of the difference in percentage receiving services between any two adjacent geographic points, divided by the closest point and averaged for all such differences on the distance scale. Direction of sign was taken into account. However, once a percentage receiving services reached zero percent, the differences between adjacent points were assumed to be $100 \%$ rather than zero. This index is intended to measure the speed with which a given service approaches zero percent, taking into account that some services are generally used more than others.

6. Family types were defined by two items (Litwak, 1985) as follows: (a) "If a married child has a chance to get a much better job out of town but it means moving away from parent, should the job be turned down in order to stay near parents or should it be accepted?" (b) "How important is it for parents and their married children to keep in touch? Would you say it is very important, important, not important, very unimportant?"

The 943 respondents who said the child should take the job and it was very important to keep in touch were defined as modified extended, the 99 who said the child not take the job and it was very important to keep in touch were defined as traditional, and the 252 who said they should take the job and it was not necessary to keep in touch were defined as isolated marital. Thirteen could not be classified; they said children should not take the job and they should not keep in touch.

7. These effects turn out to be indirect. Table 2 shows that traditional kin structure has no consistent relation to household services when proximity is controlled. However, having a traditional kin norm is more likely to lead to close proximity. For a path model presentation, see Litwak (1985: 135-139). 
8. Table 2 suggests that marital status of the helper has small and scattered relation to services. However, a path model (Litwak, 1985) shows it has a substantial indirect effect (i.e., it effects proximity).

9. Education is used as an indicator of income in Table 2 because approximately $20 \%$ of respondents did not supply an income figure, and the same pattern of relations held for both. The path analysis (Litwak, 1985: 135-139) shows that education does significantly relate to proximity.

10. Traditional kin may reject the offers of help from professionals (Gans, 1962). By contrast, modified extended kin, weakened by illness and poverty, legitimize such help.

\section{REFERENCES}

Anderson, Michael. 1977. "The impact on the family relationships of the elderly of changes since Victorian times in governmental income-maintenance provision." Pp. 36-59 in Ethel Shanas and Marvin B. Sussman (eds.), Family, Bureaucracy, and the Elderly. Durham, NC: Duke University Press.

Berkman, Lisa F. 1985. "The relationship of social networks and social supports to morbidity and mortality. Pp. 241-263 in Sheldon Cohen and S. Leonard Syme (eds.), Social Support and Health. New York: Academic Press.

Blau, Zena S. 1981. Black Children/White Children: Competence, Socialization, and Social Structure. New York: Free Press.

Burgess, Ernest W., Paul Wallin, and G. D. Schultz. 1953. Courtship, Engagement and Marriage. Philadelphia: J. B. Lippincott.

Gans, Herbert J. 1962. The Urban Villager. New York: Free Press, 1962.

Hanlon, Martin D. 1982. "Primary group assistance during unemployment." Human Organizations 41: 156-161.

Horowitz, Amy. 1985. "Sons and daughters as caregivers to older parents: Differences on role performance and consequences. Gerontologist 25: 612-617.

Horwitz, Allan. 1977. "Social networks and pathways into psychiatric treatment." Social Forces 56: 86-103.
Katz, Elihu, and Paul F. Lazarsfeld. 1955. Personal Influence. Glencoe, IL: Free Press.

Kendig, Hal. 1983. "Blood ties and gender roles: Adult children who care for aged parents." In Proceedings of the Australian Family Research Conference (Vol. 5): Family Support Networks. Melbourne, Australia: Institute of Family Studies.

Litwak, Eugene. 1960. "Geographical mobility and extended family cohesion." American Sociological Review 25: 385-394.

Litwak, Eugene. 1965. "Extended kin relations in an industrial society."' Pp. 290-323 in Ethel Shanas and Gordon Striebe (eds.), Social Structure and the Family Generational Relations. Englewood Cliffs, NJ: Prentice-Hall.

Litwak, Eugene. 1985. Helping the Elderly: The Complementary Roles of Informal Networks and Formal Systems. New York: Guilford Press.

Litwak, Eugene, and Cecile Falbe. 1983. "Formal organizations and community primary groups: Theory and policy of shared functions as applied to the aged." In Richard H. Hall and Richard E. Quinn (eds.), Organizational Theory and Public Policy. Beverly Hills, CA: Sage Publications.

Litwak, Eugene, and Josefina Figueira. 1968. "Technological innovations and theoretical functions of primary groups and bureaucratic structures." American Journal of Sociology 73: 468-481.

Parsons, Talcott. 1944. "The social structure of the family." In R. Anshen (ed.), The Family: Its Function and Destiny. New York: Harper and Row.

Polsky, Howard, and Louise Duberman. 1979. "The changing American family: From traditional to companionship to existential." Pp. 158-170 in Howard Polsky (ed.), Social System, Culture, and Role Theory: Applications in the Helping Professions. Lexington, MA: Ginn Custom Publishing.

Rix, Sarah E., and Tania Romashko. 1980. With a Little Help from My Friends: Final Report to Administration on Aging. U.S. Government AOA Grant No. 90-A-1320. Washington, DC: Department of Health, Education, and Welfare.

Shanas, Ethel. 1979. "The family as a support system in old age." Gerontologist 19: 169-174.

Sussman, Marvin B. 1977. "Family bureaucracy and the elderly individual: An organizational linkage perspective." In Ethel Shanas and Marvin Sussman (eds.), Family, Bureaucracy, and the Elderly. Durham, NC: Duke University Press.

Young, Michael, and Peter Willmott. 1957. Family and Kinship in East London. London: Routledge and Kegan Paul. 